\title{
MiR-214 increases the sensitivity of breast cancer cells to tamoxifen and fulvestrant through inhibition of autophagy
}

\author{
Xinfeng Yu', Aiping Luo², Yicong Liu', Shuqing Wang ${ }^{1}$, Ye Li ${ }^{3}$, Wenna Shi', Zhihua Liu² and Xianjun $\mathrm{Qu}^{1 *}$
}

\begin{abstract}
Background: Tamoxifen (TAM) and fulvestrant (FUL) are the major drugs for patients with estrogen receptorpositive $\left(\mathrm{ER}^{+}\right)$breast cancers. However, the development of endocrine resistance is the impediment for successful treatment. We aimed to explore the mechanisms of endocrine resistance and therapeutic strategy for overcoming resistance against TAM and FUL.

Methods: Experiments were performed in $\mathrm{ER}^{+}$and estrogen/TAM-sensitive MCF7 cells and antiestrogen-resistant MCF7/LCC9 cells. The expression of miR-214 and uncoupling protein 2 (UCP2) was determined by RT-qPCR and Western blot in breast cancer cells and human breast cancer tissue specimens. Cell autophagy was examined by fluorescent probe monodansyl cadaverine (MDC) and GFP-LC3-II-positive punctate identified by confocal microscopy. Apoptotic cells were determined by Annexin V-FITC/PI staining. The potential regulatory target of miR-214 was determined by prediction tool, target protein expression and luciferase reporter assay.
\end{abstract}

Results: 4-OHT/FUL treatment resulted in induction of apoptosis as well as autophagy in breast cancer cells. Autophagy might be the major cause of endocrine resistance to 4-OHT or FUL. MiR-214 increased the sensitivity of breast cancer cells to the 4-OHT/FUL-induced apoptosis through inhibition of autophagy. Importantly, a negative correlation was established between miR-214 and UCP2 in human breast cancer tissue specimens assayed by RT-qPCR. UCP2 was identified to be a direct target of miR-214. Further study in MCF7/LCC9 cells indicated that endocrine resistance might arise from activation of the PI3K-Akt-mTOR pathway, thereby inducing autophagy by overexpression of UCP2.

Conclusion: MiR-214 increased the sensitivity of breast cancer cells to TAM and FUL through inhibition of autophagy by targeting UCP2. MiR-214 shows potential as a novel therapeutic strategy for overcoming endocrine resistance in $\mathrm{ER}^{+}$breast cancers.

Keywords: ER ${ }^{+}$breast cancer, Endocrine resistance, Apoptosis, Autophagy, MiR-214, UCP2

\section{Background}

Breast cancer is one of the most prevalent cancers in women worldwide, with almost 1.2 million new cases diagnosed each year [1]. Breast cancers are classified based on the expression of hormone receptors: estrogen receptor (ER), progesterone receptor (PR), and human epidermal growth receptor 2 (HER2). Among those patients, about $70 \%$ of cases express ER. In patients with metastatic breast

\footnotetext{
* Correspondence: quxj@ccmu.edu.cn

${ }^{1}$ Department of Pharmacology, School of Basic Medical Sciences, Capital Medical University, No.10, Xitoutiao, Youanmenwai Avenue, 100069 Beijing, China

Full list of author information is available at the end of the article
}

cancer, the percentage of cases with ER reaches $75 \%[2]$. Targeting estrogen and its receptors is therefore an important strategy in endocrine therapies for breast cancers. Commonly used drugs include (a) tamoxifen (TAM) and (b) fulvestrant (FUL). TAM has been used as an antiestrogen agent for many years. TAM physically competes with estrogens to bind to ER, thereby preventing the proliferative stimuli of estrogens [3]. Unlike TAM, FUL is a pure ER antagonist which competitively binds to ER, leading to its downregulation in cancer cells. FUL is specifically indicated for treatment of postmenopausal patients with $\mathrm{ER}^{+}$ metastatic breast cancer $[4,5]$. 
Although these drugs are initially effective, overall clinical benefit from use of them is often eventually limited by the development of endocrine resistance. TAM, for instance, is not effective in approximately $30 \%$ of patients and resistance is observed in $50 \%$ of patients eventually after treatment [6]. After prolonged therapy with FUL, therapy resistance eventually develops in most of patients and recurs with metastatic disease $[5,7]$. Multiple mechanisms responsible for endocrine resistance are recognized, such as deregulation of the ER pathway itself, alterations in cell cycle and survival molecules, and altered expression of miRNAs $[8,9]$. Recently, the noteworthy mechanism of endocrine resistance is the increase of autophagy and apoptosis in the $\mathrm{ER}^{+}$breast cancers following TAM treatment [10]. In fact, autophagy and apoptosis pathways are tightly connected with each other by substantial interplays, enabling the coordinated regulation of cell fates by these two pathways. Studies have shown that autophagy occurs when the apoptotic machinery is imperfect, detailed mechanisms underlying are not clearly understood [11, 12]. Autophagy is an evolutionarily conserved mechanism of cellular self-digestion in which proteins and organelles are degraded through delivery to lysosomes. The process of autophagy pathway is regulated by a variety of signaling molecules [13]. Since autophagy is involved in the process of pathological disorders with a shift in balance between cell death and survival in response to TAM, increase of autophagy was thus recognized as an important mechanism of TAM resistance [14]. Inhibition of autophagy might potentiate resensitization of previously antiestrogen resistant breast cancer cells [6]. However, a balance might exist between autophagy and apoptosis in response to the endocrine therapy. The key point in the determination of cell fate appears to be affected by the status of cancer cells in autophagy or apoptosis [15].

MiRNAs are a class of short, endogenous, noncoding RNAs ( 20-24 nucleotides) that regulate the expression of a wide variety of genes. Through base pairing with the 3 '-untranslated region (3'UTR) of target genes, miRNAs were found to enhance mRNA degradation or inhibit posttranscriptional translation [16, 17]. Mountains of reports showed that miRNA alteration or dysfunction might play important roles in tumorigenesis and cancer metastasis by the way of regulating cancer cell proliferation, differentiation, apoptosis and invasion [18]. Notably, miRNAs were found to function in the regulation of autophagy. For instance, miR-101 was identified as a potent inhibitor of basal, etoposide- and rapamycininduced autophagy [19]. MiR-214 is often dysregulated in various cancers and its functions vary largely with tissue types. The upregulation of endogenous miR-214 has been linked with increased proliferation, migration, invasion, extravasation and metastasis in specific cancer types, such as pancreatic, cervical, hepatocellular, gastric, prostate and ovarian cancer [20]. By contrast, the downregulation of this miR has been associated with cancer progression and metastasis in some other caner types, such as breast cancers, suggesting that tight regulation of miR-214 is important for cellular function [21, 22]. In addition, miR-214 has been shown to induce apoptosis in some cancer types [23]. In our pilot study, miR-214 was found downregulated in human breast cancer tissue specimens. Using $\mathrm{ER}^{+}$breast cancer cell lines, miR-214 increased the sensitivity of cancer cells to TAM and FUL through inhibition of autophagy. Upregulation of miR214 led to the inhibition of breast cancer growth and invasion [22]. MiR-214 was thus considered as a tumor suppressor in many cancers. However, functional relevance of these findings and mechanisms has not been fully addressed. In this study, we examined the effects of miR-214 on sensitivity of breast cancer cells to TAM and FUL in the $\mathrm{ER}^{+}$and estrogen/TAM-sensitive MCF7 cells and antiestrogen-resistant MCF7/LCC9 cells. The biochemical mechanisms behind the effects of miR-214 were then investigated.

\section{Methods}

\section{Human breast cancer tissue specimens}

This section of experiment was approved by the Institutional Review Board of the Chinese Academy of Medical Sciences Cancer Institute, and written informed consents were obtained from all patients. No patients received any type of endocrine therapy. Twenty pairs of breast cancer tissue specimens and adjacent normal mucosa were obtained from Chinese Academy of Medical Sciences Cancer Hospital (Beijing, China). Each pair of cancer specimen and adjacent normal tissue was confirmed by pathological analysis. All tissues were immediately frozen in liquid nitrogen after surgical removal until use for real-time-qPCR analysis.

\section{Cell culture and drug treatment}

Human breast cancer cell line MCF7 was purchased from American Type Culture Collection (ATCC, Rockville, $\mathrm{MD})$. MCF7 is the ER positive and estrogen/TAM-sensitive cell line. MCF7 cells were grown in DMEM medium supplemented with $10 \%$ fetal bovine serum (FBS) and $0.01 \mathrm{mg} / \mathrm{ml}$ insulin at $37{ }^{\circ} \mathrm{C}$ in a humid atmosphere $\left(5 \% \mathrm{CO}_{2}-95 \%\right.$ air). MCF7/LCC9 cell line is a fully antiestrogen-resistant MCF7 variant exhibiting cross resistance to FUL and TAM [24]. MCF7/LCC9 was provided by Dr. Robert Clarke (Georgetown University). MCF7/LCC9 cells were maintained in phenol-red free DMEM containing $5 \%$ dextran charcoal-stripped FBS (DCC-FBS) and $100 \mu \mathrm{g} / \mathrm{ml}$ penicillin. 
Prior to treatment, cells were exposed to $5 \%$ DCCFBS for $48 \mathrm{~h}$ (serum-starved). Cells were then treated with $5 \mu \mathrm{M}$ 4-hydroxytamoxifen (4-OHT, Sigma-Aldrich) or $1 \mu \mathrm{M}$ FUL (Sigma-Aldrich) for 48 or $72 \mathrm{~h}$ in the presence or absence of $5 \mathrm{mM}$ 3-methyladenine (3-MA, Sigma-Aldrich). $0.1 \%$ ethanol was used as vehicle control (0.01\% final volume).

\section{Plasmids construction and cell transfection}

To produce UCP2 expression plasmid, full length of UCP2 coding region was amplified by PCR using sequence-specific primers (forward: 5'-cgcGGATCCaggacgtagcaggaaatcagc-3', reverse: 5'-gcTCTAGAagaggtgatcaggtcagcag-3', containing restriction sites for BamH1 and $\mathrm{XbaI}$ respectively). The double digested $\mathrm{cDNA}$ was inserted into pcDNA3.1-HisC plasmid and confirmed by sequencing. For UCP2 knockdown assay, the siRNA against UCP2 was synthesized by GenePharma (Shanghai, China). The oligonucleotide sequences were 5'-GCACCGUCAAUGCCUACAATT-3'. MiR-214 mimics and inhibitors were also purchased from GenePharma (Shanghai, China). Transient transfection of UCP2 plasmid and siRNA or miRNA was performed with Lipofectamine 2000 (Invitrogen) according to manufacturer's instructions. MCF7 or MCF7/LCC9 cells were transfected either with $200 \mathrm{nM}$ UCP2 siRNA or $100 \mathrm{nM}$ miR-214 mimics/inhibitors for $48 \mathrm{~h}$. Corresponding negative control was concurrently used in all experimental system. Cells were harvested for RT-PCR or Western blotting analysis.

\section{RNA extraction and RT-qPCR}

Total RNA was extracted using TRIzol (Invitrogen) in accordance with manufacturer's protocol. Reverse transcription of total miRNA was performed by using a miScript reverse transcription kit (Qiagen). MiScript SYBR Green PCR kit (Qiagen) together with a pair of miR-214 specific primers was used for mature miRNA detection. RNU6B was used as an internal normalized reference.

For detection of UCP2 mRNA expression, total RNA was reversely transcribed by using SuperScript III First-Strand Synthesis System (Invitrogen) according to manufacturer's instruction. Real-time PCR was performed in triplicate in an ABI 7900HT real-time PCR system (Applied Biosystems) with a $20 \mu$ reaction mixture containing Brilliant II SYBR Green qPCR master mix and 300 nM UCP2 primers. Primer sequences for UCP2 were 5'-cgcatcggcctgtatgattc-3' and 5'- cataggtcaccagctcagc3'. Primer sequences for GAPDH were 5'-gagtcaacggatttggtcgt-3' and 5'-ttgattttggagggatctcg-3'. The thermal cycling was initiated by polymerase activation step for $10 \mathrm{~min}$ at $95{ }^{\circ} \mathrm{C}$ followed by 40 cycles of denaturation ( $95^{\circ} \mathrm{C}$ for $30 \mathrm{~s}$ ) and annealing/extension $\left(60^{\circ} \mathrm{C}\right.$ for $\left.1 \mathrm{~min}\right)$. Relative expression of UCP2 was normalized to GAPDH as an internal control and determined by a previously described method [25].

\section{Western blotting analysis}

Cells were harvested and lysed in radioimmune precipitation assay (RIPA) buffer. Protein was extracted and concentration was determined by using a BCA kit (Thermo Fisher Scientific). Equal amounts of cell lysates were resolved by SDS-PAGE and transferred to PVDF membranes (Millipore). After blocking in $5 \%$ nonfat milk for $1 \mathrm{~h}$, the membranes were immunoblotted overnight at $4{ }^{\circ} \mathrm{C}$ with primary antibodies against LC3, beclin-1, caspase-9, Bcl-2, PARP (Cell Signaling Technology) and Bax (Santa Cruz) followed by incubation with polyclonal HRP-conjugated secondary antibodies for $1 \mathrm{~h}$ at room temperature. Immunoreactive products were visualized by chemiluminescence (Pierce Biotechnology) and quantified by densitometry using Quantity One software. Densitometric analyses of bands were normalized with $\beta$-actin functioning as a loading control.

\section{Cell viability assay}

MCF7 cells seeded in 6-well plate were transfected with $100 \mathrm{nM}$ negative control or miR-214 mimics and inhibitors for $24 \mathrm{~h}$. Cells were trypsinized into 96-well plates at a density of $8 \times 10^{3}$ cells/well and then treated with 5 $\mu \mathrm{M} 4-\mathrm{OHT}$, or $1 \mu \mathrm{M}$ FUL for $72 \mathrm{~h}$.. Cell viability was estimated by the 3-[4,5-dimethylthiazol-2-yl]-2,5-diphenyltetrazolium bromide (MTT) assay.

\section{Annexin V-FITC/PI staining assay}

MCF7 cells grown in 6-well plate were transfected with $2 \mu \mathrm{g}$ UCP2 expression plasmid, 200 nM UCP2 siRNA or $100 \mathrm{nM}$ miR-214 mimics and inhibitors as well as corresponding negative control for $24 \mathrm{~h}$. Cells were then treated with $5 \mu \mathrm{M}$ 4-OHT for additional $48 \mathrm{~h}$ in $5 \%$ DCC-FBS/DMEM. Cells were harvested and washed with cold PBS. Levels of phosphatidylserine on cell surface were quantitatively estimated by using Annexin Vfluorescein isothiocyanate (FITC) and Propidium Iodide (PI) apoptosis detection kit according to manufacturer's instruction (Bioscience). Apoptotic cells were analyzed in a flow cytometer (Guava easyCyte) using FL1 (excitation $488 \mathrm{~nm}$, green) and FL3 (excitation $585 \mathrm{~nm}$, red) channels. A minimum of 10,000 events was collected for each sample. Results were expressed as percentage of apoptotic cells relative to total cells.

\section{Cell autophagy analysis}

Cells were transfected with GFP-LC3 plasmid (Addgene) and then treated with $0.1 \% \mathrm{v} / \mathrm{v}$ ethanol vehicle or $5 \mu \mathrm{M} 4$ OHT or $1 \mu \mathrm{M}$ FUL for $48 \mathrm{~h}$. GFP-LC3-II-positive punctate pattern was observed under confocal microscope 
a
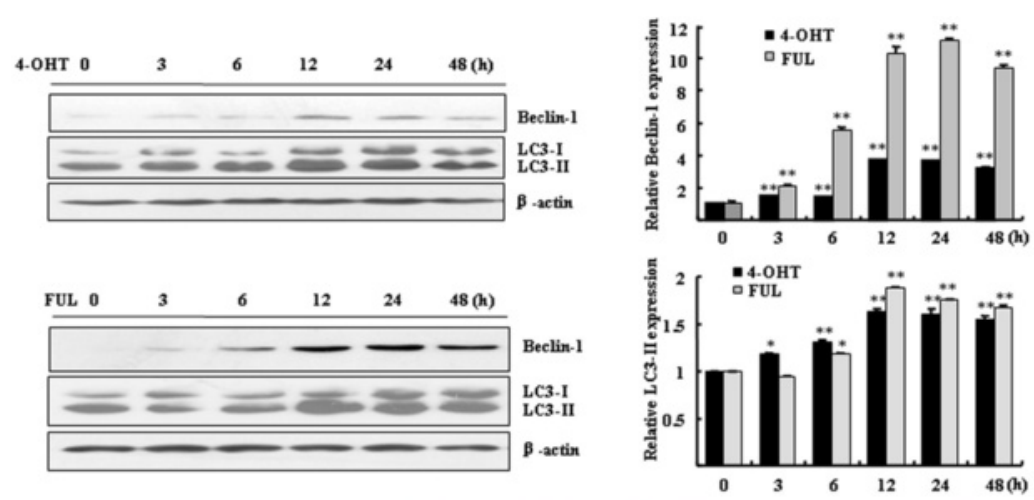

b coN
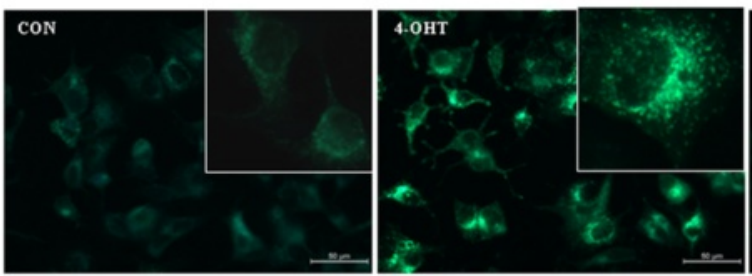

4.0HT+3MA
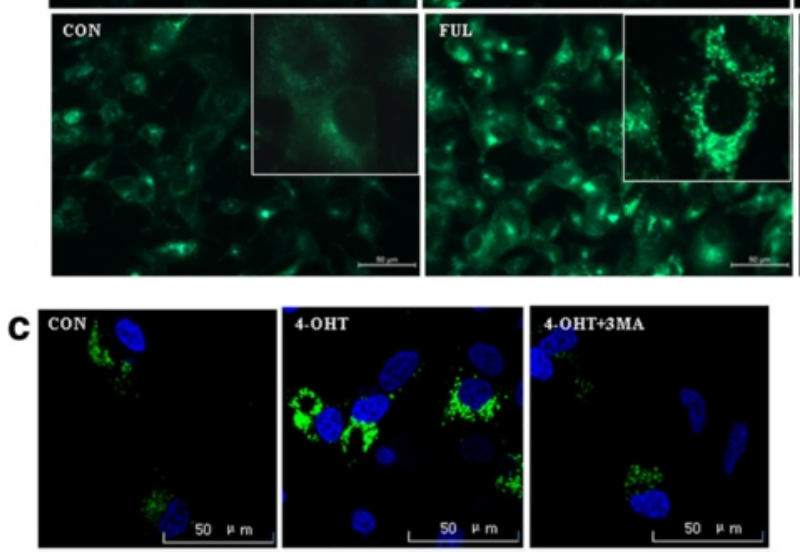

4. ОHT+3MA
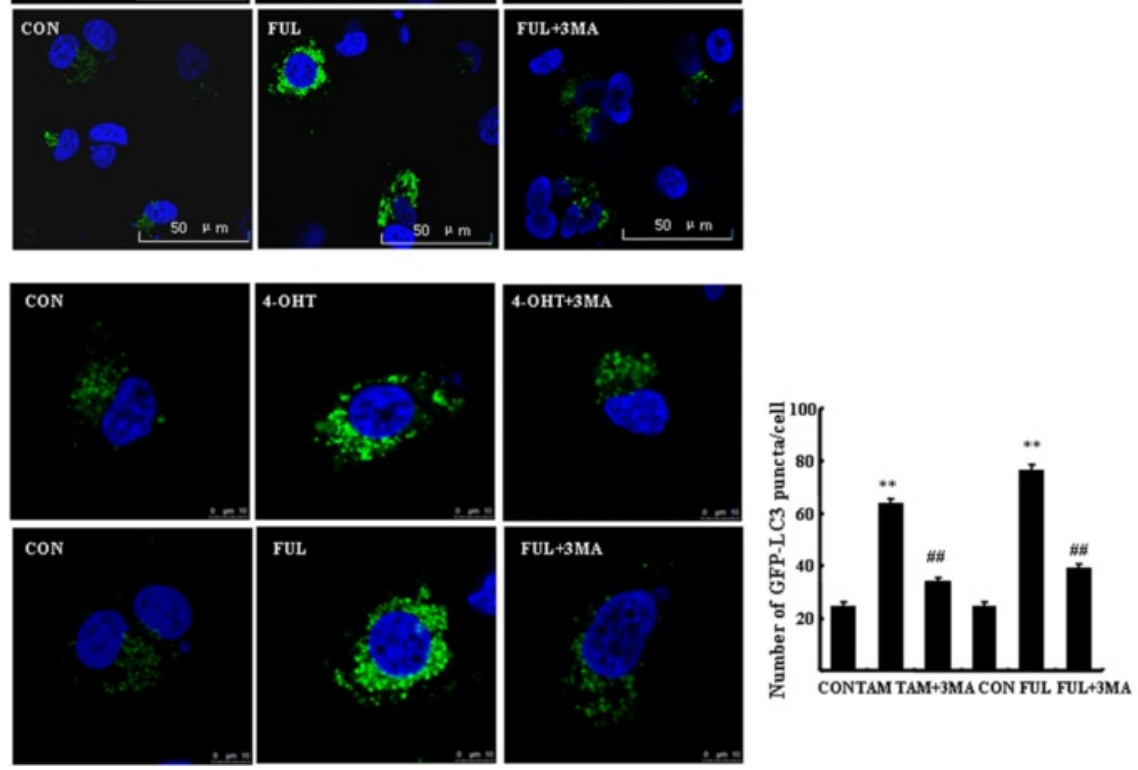

Fig. 1 (See legend on next page.) 
(See figure on previous page.)

Fig. $14-\mathrm{OHT}$ or FUL induced autophagy in breast cancer cells. a MCF7 cells were exposed to $5 \mu \mathrm{M}$ 4-OHT or $1 \mu \mathrm{M}$ FUL for the indicated time. Western blotting was performed to determine the expressions of LC3 and Beclin-1. Bar graphs indicated relative levels of LC3-II and Beclin-1 normalized to $\beta$-actin. Data represent mean \pm SD of three experiments. ${ }^{*} P<0.05,{ }^{*} P<0.01$ vs. vehicle control. b MCF7 cells seeded on coverslips were treated with $5 \mu \mathrm{M}$ 4-OHT or $1 \mu \mathrm{M}$ FUL for $48 \mathrm{~h}$. After staining with MDC, cells were imaged under a fluorescence microscope (scale bar $=50 \mu \mathrm{m})$, with a magnified image showing punctate pattern. c MCF7 cells were transfected with GFP-LC3 for $24 \mathrm{~h}$ and then were treated with $5 \mu \mathrm{M} 4-\mathrm{OHT}$ or $1 \mu \mathrm{M}$ FUL with or without $5 \mathrm{mM}$ 3-MA for $48 \mathrm{~h}$. Cells were imaged under a confocal microscopy, scale bar $=50 \mu \mathrm{m}$ (up) or $10 \mu \mathrm{m}$ (bottom). Numbers of GFP-LC3 puncta per cell were counted. ${ }^{*} P<0.01$ vs. vehicle control, ${ }^{\# \#} P<0.01$ vs. TAM/FUL treatment, $n=10$ cells. Data represent mean $\pm S D$ of three experiments

(Leica TCS SP5) equipped with oil immersion lens $(40 \times)$ with 405- and 488-nm excitation lasers. Numbers of autophagosomes were counted by using the Image J program (National Institutes of Health).

\section{Staining of autophagic vacuoles by monodansyl cadaverine (MDC)}

Fluorescent probe MDC is a selective marker for acidic vesicular organelles to evaluate autophagy. MCF7 cells grown on coverslips were treated with $5 \mu \mathrm{M} 4-\mathrm{OHT}$ for $48 \mathrm{~h}$. Cells were then exposed to $50 \mu \mathrm{M}$ MDC (SigmaAldrich) at $37{ }^{\circ} \mathrm{C}$ for $15 \mathrm{~min}$ in the dark for staining. After washing with PBS, cells were visualized under fluorescence microscope (Leica, Wetzlar, Germany).

\section{Plasmid construction and luciferase reporter assay}

To generate luciferase constructs for evaluating miRNA activity, 3' UTR of UCP2 gene was amplified using the primers whose sequences were 5'-gcGAGCTCgcctctcctgctg ctgacc-3'and 5'-gcTCTAGAatggatgacaagtgggctagg-3'. PCR was performed with genomic DNA and digested by both Sac I and Xba I and cloned into a modified pGL3-control vector pISO provided by Dr. Zhihua Liu [26]. A pair of primer 5'-gcGAGCTCgcctctcctgatactgacctgatcacc-3' and 5'gcTCTAGAatggatgacaagtgggctaggctggg-3' was used to generate mutation in the seed region binding sites. Wild type and mutant inserts were confirmed by sequencing.

For luciferase reporter assay, MCF7 cells seeded in a 96-well plate were co-transfected with firefly luciferase constructs (100 ng) and $40 \mathrm{nM}$ miRNA mimics using lipofectamine 2000 reagent. Cells were also transfected with $10 \mathrm{ng}$ of pRL-SV40 plasmid to monitor transfection efficiency. $36 \mathrm{~h}$ after transfection, firefly luciferase activity was evaluated by using a dual-luciferase reporter assay system (Promega Corporation). Renilla luciferase activity was evaluated to normalize firefly luciferase activity for each sample. Transfections were performed in triplicate and the experiments were repeated twice.

\section{Immunofluorescence staining analysis}

MCF7 cells grown on cover-slips were fixed in $4 \%$ paraformaldehyde for $10 \mathrm{~min}$ at room temperature. Cells were washed in PBS, blocked with $5 \%$ bovine serum albumin (BSA) supplemented with $0.3 \%$ Triton X-100 in PBS for $1 \mathrm{~h}$. Cells were incubated with primary antibody (UCP2, Santa Cruz) in $1 \%$ BSA at $4{ }^{\circ} \mathrm{C}$ overnight. After washing with PBS, cells were incubated with Rhodamine-labeled anti-goat secondary antibody (ZSGBBio, Beijing) in $1 \% \mathrm{BSA}$ for $1 \mathrm{~h}$ at room temperature. Cells were washed and cellular nuclei were stained with Hoechst 33342 (Sigma-Aldrich) for $10 \mathrm{~min}$. Images were acquired under confocal microscope (TCS SP5, Leica).

\section{Statistical analysis}

All data are presented as mean \pm SD. Statistical differences were evaluated by analysis of variance (ANOVA) followed by Dunnett (multiple comparisons to the same control) post hoc tests. Values of $P<0.05$ were considered as statistically significant.

\section{Results}

4-OHT/FUL treatment induces autophagy in breast cancer cells

Human $\mathrm{ER}^{+}$MCF7 cells were exposed to $5 \mu \mathrm{M}$ 4-OHT, an active metabolite of TAM, or $1 \mu \mathrm{M}$ FUL for different time and then the characteristics of autophagy was analyzed. Beclin-1 is one of markers that critically indicate the process of autophagosomic-lysosomal degradation of proteins activated in response to pathological disorders. 4-OHT and FUL treatment increased the expression of beclin-1 time-dependently. The increase of beclin-1 reached a peak at $12 \mathrm{~h}$ after exposure and remained at high levels up to $48 \mathrm{~h}$ (Fig. 1a). LC3-II, the cleaved and lipidated form of the microtubule associated protein light chain 3 (MAP1LC3), is the hallmark protein signifying the increase of autophagy. 4-OHT/FUL treatment led to elevation of LC3-II, which reached plateau during time from 12 to $48 \mathrm{~h}$.

The 4-OHT/FUL-induced autophagy was also seen after staining with acidic vesicular organelles (AVOs). Figure $1 \mathrm{~b}$ showed the morphological change of autophagy in the 4-OHT/FUL-treated cells. A significant increase of MDC fluorescent intensity was observed in the 4-OHT/ FUL-treated cells, showing an increased fraction of cells with punctate staining distributed within cytoplasm or perinuclear regions. We added 3-MA, an autophagy inhibitor, to the 4-OHT/FUL-treated cells. The formation of autophagosomes was obviously inhibited (Fig. 1b). 


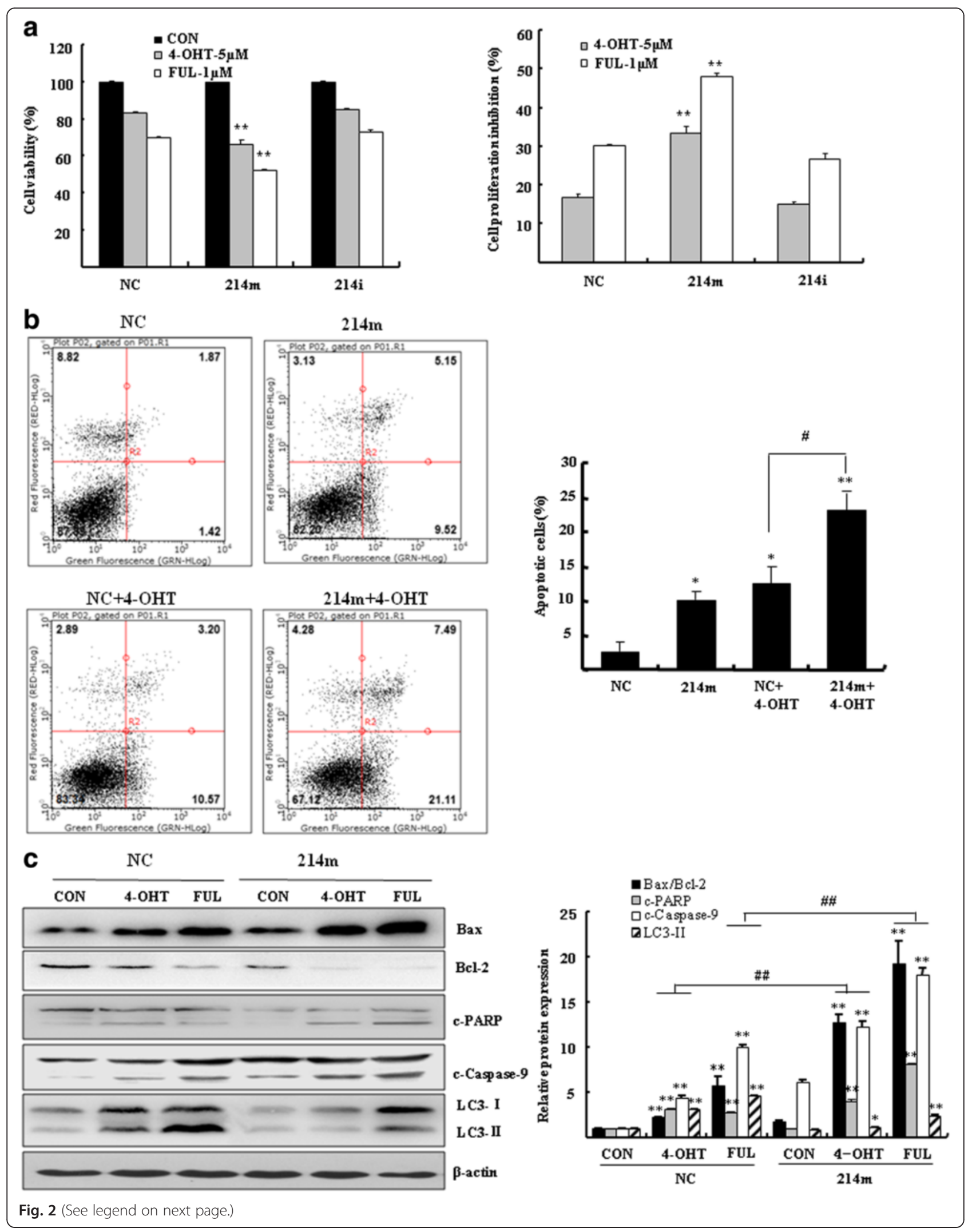


(See figure on previous page.)

Fig. 2 MiR-214 increased the TAM/FUL-induced apoptosis in breast cancer cells. a MCF7 cells were transfected with 100 nM miR-214 mimics $(214 \mathrm{~m}$ ) or inhibitors (214i) for $24 \mathrm{~h}$. Cells were then treated with $5 \mu \mathrm{M}$ 4-OHT or $1 \mu \mathrm{M}$ FUL for $72 \mathrm{~h}$. Cell viability was estimated by the MTT assay. b MCF7 cells were transfected with $100 \mathrm{nM}$ miR-214 mimics $(214 \mathrm{~m}$ ) or negative control (NC). Cells were then treated with or without $5 \mu \mathrm{M} 4-\mathrm{OHT}$ for $48 \mathrm{~h}$. Annexin V-PI double staining was performed by flow cytometry. Bar graphs indicated the percentage of apoptotic cells. Data represent mean $\pm \mathrm{SD}$ of three experiments. ${ }^{*} P<0.05$, ${ }^{* *} P<0.01$ vs. negative control $(\mathrm{NC}),{ }^{\sharp} P<0.05$ vs. negative control treated with $4-\mathrm{OHT}$ (NC $+4-\mathrm{OHT}$ ) (c) Western blotting was performed to analyze the expression of apoptotic proteins Bax, Bcl-2, c-PARP (cleaved PARP), cleaved-caspase-9 (c-capase-9) and autophagic protein LC3-II. Bar graphs indicated relative levels of Bax/BCl-2, c-PARP, c-capase-9 and LC3-II normalized to $\beta$-actin. ${ }^{*} P<0.05$, ${ }^{* *} P<0.01$ vs. vehicle control, ${ }^{\# \#} P<0.01$ vs. negative control (NC)

MCF7 cells were transfected with GFP-LC3 plasmid and GFP-LC3-II puncta was analyzed in autophagic cells. The number of autophagosomes (GFP-LC3-II dots) was then counted in the 4-OHT/FUL-treated cells. 4OHT/FUL treatment significantly increased GFP-LC3 puncta in MCF7 cells (Fig. 1c). However, in the presence of 3-MA, the formation of autophagosomes was inhibited (Fig. 1c, bottom, $P<0.01$, vs. vehicle control).

\section{MiR-214 increases the 4-OHT/FUL-induced cell apoptosis} By binding to ER, the effect of 4-OHT/FUL mainly depends on the activity of apoptotic induction. In order to find miRNAs that sensitize the 4-OHT/FUL-induced apoptosis, cell proliferation and apoptosis were examined in the miRNAs-transfected MCF7 cells. MiR-214 was considered as an important mediator in the sensitization of the 4-OHT/FUL-induced apoptosis. The proliferation of MCF7 cells was inhibited by $16.7 \pm 1.1 \%$ by $4-\mathrm{OHT}$ (Fig. 2a, $P<0.01$ vs. vehicle control) and $30.0 \pm 0.6 \%$ by FUL $(P<0.01$ vs. vehicle control). When MCF7 cells were transfected with miR-214 mimics, the percentage of inhibition by 4-OHT or FUL was significantly increased as compared to negative control cells $(33.3 \pm 2.1 \%$ by 4 $\mathrm{OHT}$, and $47.8 \pm 1.1 \%$ by FUL, respectively, $P<0.01$ ). These results indicated that MCF7 cells transfected with miR-214 mimics exhibited higher sensitivity to 4-OHT/ FUL than the cells transfected with negative control miRNA. However, miR-214 inhibitor did not significantly affect the viability of MCF7 cells treated with 4-OHT/FUL.

MiR-214 increased the effect of the 4-OHTinduced apoptosis. As shown in Fig. 2b, the percentage of apoptotic cells was $12.4 \pm 2.6 \%(P<0.05$ vs. negative control) in MCF7 cells exposed to 4-OHT. Cells transfected with miR-214 mimics demonstrated higher levels of apoptosis than negative control cells $(P<0.05)$. When these cells were exposed to 4 -OHT, the percentage of apoptotic cells was significantly increased to $23.2 \pm 2.9 \%(P<0.01$ vs. negative control) . There was a significant difference in the percentage of apoptotic cells between the miR-214-transfected cells and negative control cells in response to 4-OHT treatment (Fig. 2b, $P<0.05$ ).

The effect of miR-214 mimics in improving the sensitization of breast cancer cells to the 4-OHT-induced apoptosis was further evaluated at the protein levels. Both 4-OHT and FUL significantly increased the ratio of Bax/ Bcl-2, the levels of cleaved PARP and cleaved caspase- 9 in MCF7 cells. Cells transfected with miR-214 mimics had higher levels of apoptotic proteins than negative control cells in response to 4-OHT or FUL exposure (Fig. 2c, $P<0.01$ vs. vehicle control). Since autophagy plays a prosurvival role and contributes to drug resistance, it is likely that miR-214 mimics might enhance the sensitivity of breast cancer cells to the 4-OHT/FUL-induced apoptosis by the inhibition of autophagy. We analyzed the specific autophagy marker LC3 in the miR-214 mimicstransfected cells. As compared to control cells, the 4OHT/FUL-induced cleavage of LC3-I into LC3-II was significantly attenuated in the miR-214 mimics-transfected cells (Fig. 2c, $P<0.01$ vs. negative control).

\section{MiR-214 inhibits both basal and the 4-OHT/FUL-induced autophagy}

The induction of autophagy by 4-OHT/FUL was further evidenced by the elevated levels of cleaved LC3-II and beclin-1 (Fig. 3a). In fact, the level of miR-214 in these 4-OHT/FUL-treated cells was obviously reduced as compared with the vehicle control cells (Fig. 3b). These results implied that miR-214 might play important roles in the regulation of the 4-OHT/FUL-induced autophagy. Further evidence was found by Western blotting assay in MCF7 cells transfected with miR-214 mimics or inhibitors. As shown in Fig. 3c, the level of LC3-II was significantly reduced in MCF7 cells overexpressing miR-214, whereas miR-214 inhibitors stimulated the expression of cleaved LC3-II (Fig. 3c). These results indicated that miR-214 inhibited autophagy at the basal level. When cells were exposed to 4-OHT or FUL, miR-214 mimics and inhibitors had opposite effects on autophagy. As shown in Fig. 3d, in response to 4-OHT or FUL, the miR-214 mimics-transfected MCF7 cells demonstrated lower levels of LC3-II than negative control cells (Fig. 3d, above). These autophagic markers were dramatically augmented in the MCF7 cells transfected with miR-214 inhibitors (Fig. 3d, bottom). These results were also evidenced by analysis of autophagosomes under confocal microscopy. The formation of autophagosomes (GFP-LC3 dots) was significantly inhibited in the miR-214 overexpressing cells (Fig. 3e up). 


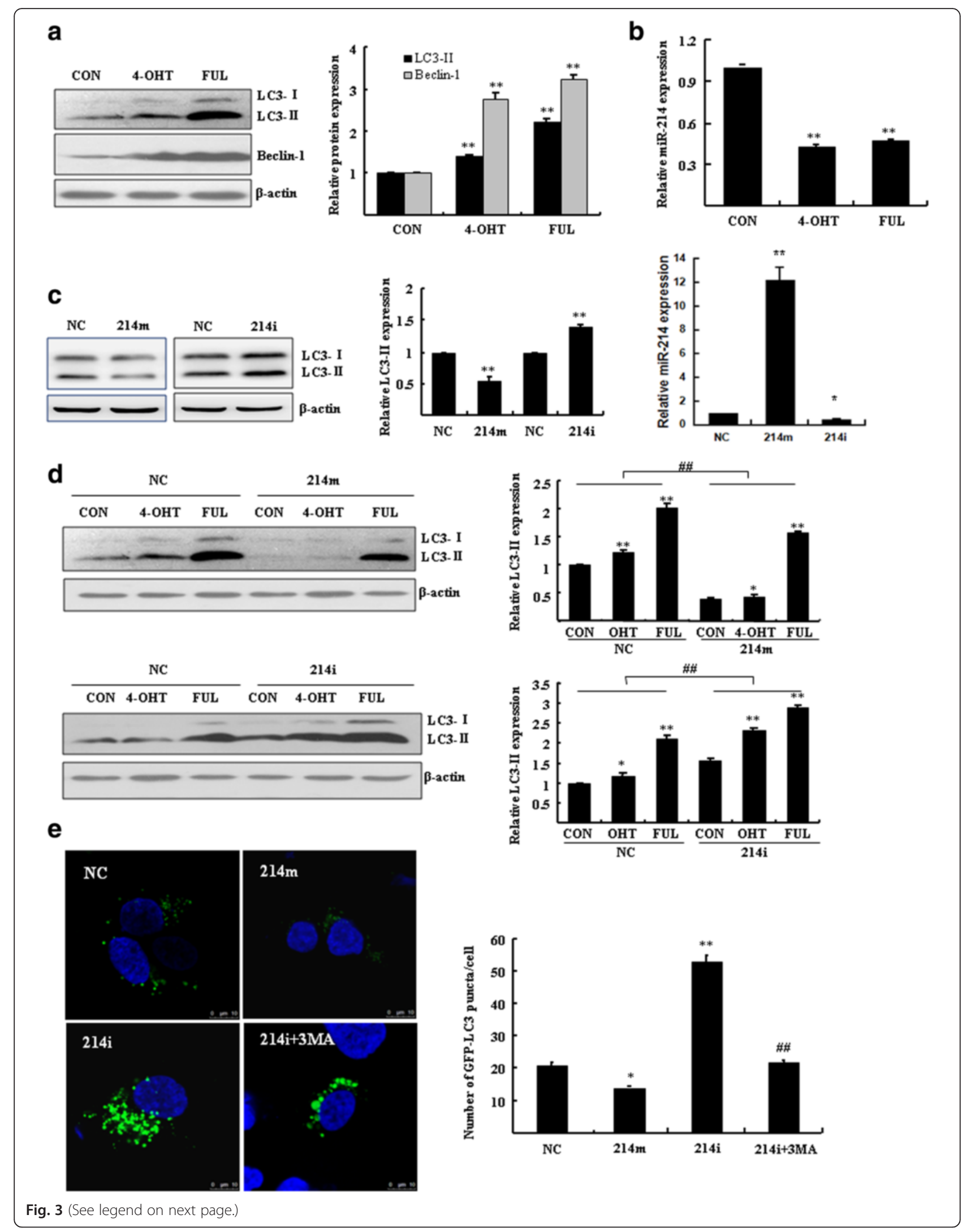


(See figure on previous page.)

Fig. 3 MiR-214 regulated autophagy at both basal and 4-OHT/FUL induced level. a MCF7 cells were treated with $5 \mu$ M 4-OHT or $1 \mu M$ FUL for $48 \mathrm{~h}$. Western blotting was performed to analyze LC3 and Beclin-1. Bar graphs indicated relative levels of LC3-II and Beclin-1 normalized to $\beta$-actin. ${ }^{* *} P<0.01$ vs. vehicle control. b The expression of miR-214 was analyzed by RT-qPCR. ${ }^{* *} P<0.01$ vs. vehicle control. $\mathbf{c}$ and d) MCF7 cells were transfected with $100 \mathrm{nM}$ miR-214 mimics $(214 \mathrm{~m}$ ) or inhibitors (214i) for $24 \mathrm{~h}$, then were treated with or without $5 \mu \mathrm{M} 4-\mathrm{OHT}$ or $1 \mu \mathrm{M}$ FUL for $48 \mathrm{~h}$. Western blotting was performed to analyze LC3-II normalized to $\beta$-actin. RT-qPCR was performed to analyze the level of miR-214 (c). ${ }^{*} P<0.05,{ }^{* *} P<0.01$ vs. vehicle control, ${ }^{\# \#} P<0.01$ vs. negative control (NC). e MCF7 cells were co-transfected with GFP-LC3 and $100 \mathrm{nM}$ miR-214 mimics or inhibitors for $48 \mathrm{~h}$ in the presence or absence of $5 \mathrm{mM}$ 3-MA. Cells were imaged under a confocal microscopy (scale $\mathrm{bar}=10 \mu \mathrm{m})$. Numbers of GFP-LC3 puncta per cell were counted $\left({ }^{*} P<0.05^{* *} P<0.01\right.$ vs. negative control, $\#$ \# $P<0.01$ vs. transfection of miR-214 inhibitors (214i), $n=10$ ). Data represent mean \pm SD of three experiments

On the contrary, the number of GFP-LC3 dots in the MCF7 cells transfected with miR-214 inhibitors was obviously increased. The increase of GFP-LC3 dots was significantly reduced by $3-\mathrm{MA}$ (Fig. 3 e bottom, $P<0.01$ ).

\section{UCP2 is a direct target of miR-214}

Having established a link between miR-214 and autophagy, we further investigated the mechanism of miR-214 by identifying its downstream targets. We employed the TargetScan program to predict the potential target genes. To our interest, UCP2, a mitochondrial protein that has been implicated in the production of intracellular Reactive oxygen species (ROS), might be targeted by miR-214. To evidence this hypothesis, we analyzed the expression of miR-214 and UCP2 in human breast cancer tissue specimens. A potential correlation of miR-214 and UCP2 was observed in 20 pairs of human breast cancer tissues and matched normal tissues. Lower level of miR-214 was observed in most of cancer tissues $(15 / 20$, $75.0 \%$ ), while UCP2 mRNA was significantly upregulated $(17 / 20,85.0 \%)$ as compared with the matched normal tissues $(P=0.0013$ and $P=0.0022$, respectively) (Fig. $4 \mathrm{a}, \mathrm{b})$. Further analysis showed that the level of miR-214 was negatively correlated with the elevation of UCP2 mRNA (Pearson $\gamma=-0.49, P=0.028$ ).

To identify the target gene of miR-214, MCF-7 cells were transfected with miR-214 mimics or negative control. The level of UCP2 mRNA was significantly reduced in the miR-214 overexpressing cells (Fig. 4c, d). The inhibitory effect of miR-214 on the expression of UCP2 protein was also analyzed by immunofluorescence assay. Figure 4e showed the images of MCF7 cells with the Rhodamine-labeled UCP2 protein located in mitochondria. The fluorescence intensity was significantly reduced by $33.1 \pm 7.6 \%$ in the miR-214 mimics-transfected cells $(P<0.01$ vs. negative control). In contrast, MCF7 cells transfected with miR-214 inhibitors produced a significant increase of $1.8 \pm 0.3$ fold in the fluorescence intensity of UCP2 as compared with negative control cells $(P<0.01$ vs. negative control).

MiR-214 was found to downregulate UCP2 by targeting the site in 3'UTR of UCP2 gene determined by dual luciferase reporter assay (Fig. 4f). The binding of miR-
214 to the target site in the 3'UTR of UCP2 was identified by cloning the wild-type (WT) and mutant UCP2 3'UTR behind the luciferase gene in pISO vector. Coexpression of UCP2-3'UTR constructs with miR-214 mimics in MCF7 cells resulted in an inhibition of the relative luciferase activity by $83.7 \pm 1.1 \%(P<0.01)$ as compared with negative control miRNA mimics; whereas miR-214 mimics did not significantly inhibit luciferase activity in the cells expressing mutant UCP2-3'UTR. These results suggested that miR-214 might directly bind to the 3'UTR of UCP2 and modulate UCP2 expression.

\section{Overexpression of UCP2 contributes to endocrine resistance to 4-OHT}

Based on the observation of relevance between UCP2 and miR-214, we hypothesized that miR-214 might increase the 4-OHT-induced apoptosis through inhibition of UCP2. We explored the role of UCP2 in affecting the 4-OHT-induced apoptosis in breast cancer cells. UCP2 expression plasmids were constructed and then transfected into MCF7 cells. The expression of UCP2 was analyzed by RT-qPCR and Western blotting (Fig. 5a, b). RNA interference assay was performed to knockdown UCP2. Results showed that the level of UCP2 mRNA was significantly reduced by $65.1 \pm 6.2 \%$ (Fig. 5 c, $P<0.01$ ). Overexpression and knockdown of UCP2 by transfection of UCP2 expression plasmid and siRNA were analyzed by immunofluorescence staining assay (Fig. 5d). Transfection of UCP2 expression plasmids or UCP2 siRNA led to a pronounced increase or decrease of Rhodamine-labeled fluorescence intensity as compared with control cells $(P<0.05)$.

Subsequently, the apoptotic cells were determined by Annexin V-Propidium Iodide (PI) staining by flow cytometry. As shown in Fig. 5e, UCP2 siRNA led to a significant increase of apoptosis in the presence or absence of 4-OHT as compared to negative control $(P<0.01)$. In contrast, UCP2 overexpression attenuated both endogenous and the 4-OHT-induced apoptosis compared with empty vector control $(P<0.01)$. These results indicated that downregulation of UCP2 increased the sensitivity of breast cancer cells to 4- 
a

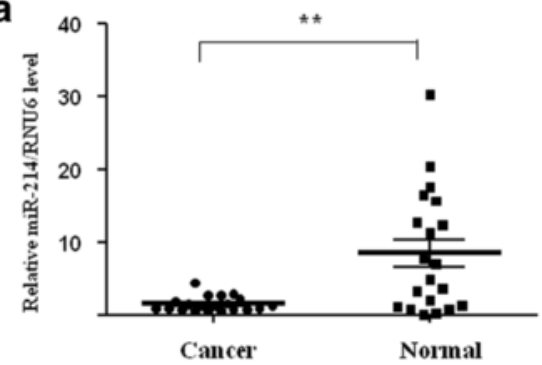

C

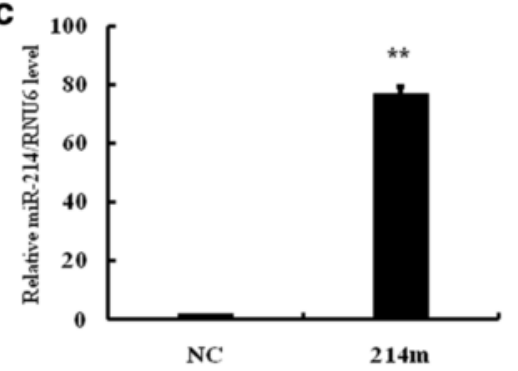

e Rodamine Hoechst Merged

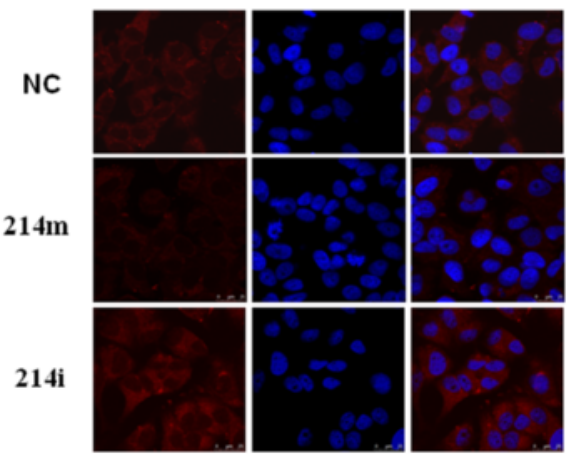

b

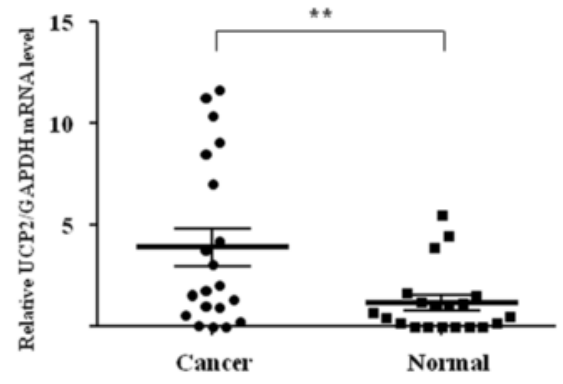

d

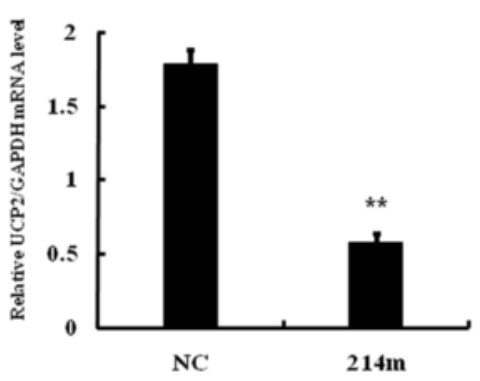

f

UCP2-3' UTR-WT 5' ...NNNNNNGCCUCUCCUGCUGCUGAC. .

Hsa-miR-214 3' UGACGGACAGACACGGACGACA

UCP2-3' UTR-MUT 5 ' ...NNNNNNGCCUCUCCUGAUUACUGAC..

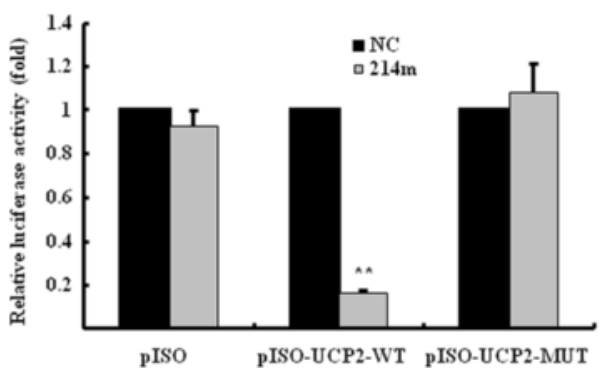

Fig. 4 UCP2 was identified the target gene of miR-214. a RT-qPCR was performed to analyze the expression of miR-214 relative to RNU6 in 20 pairs of breast cancer tissues. $\mathbf{b}$ RT-qPCR was also performed to analyze the expression of UCP2 mRNA in breast cancer tissues. $\mathbf{c}$, $\mathbf{d}$ ) MCF7 cells were transfected with $100 \mathrm{nM}$ miR-214 mimics, then RT-qPCR was performed to analyze the expression of miR-214 and UCP2 mRNA. ${ }^{* *} P<0.01$ vs. negative control (NC). e MCF7 cells were transfected with $100 \mathrm{nM}$ miR-214 mimics or inhibitors for $48 \mathrm{~h}$. The expression and location of the Rhodamine-labeled UCP2 were determined by the immunofluorescence assay. Hoechst 33342 was used to stain nuclei. Images were acquired by confocal microscopy. $\mathbf{f}$ MCF7 cells were transfected with luciferase constructs and miR-214 mimics. The comparison of luciferase activity of wild-type (WT) and mutant (MUT) UCP2 constructs was performed $36 \mathrm{~h}$ after transfection. Data was normalized to renilla activity. ${ }^{*} P<0.01$ vs. negative control (NC) 


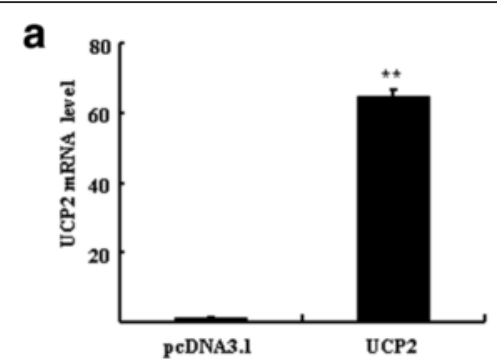

b
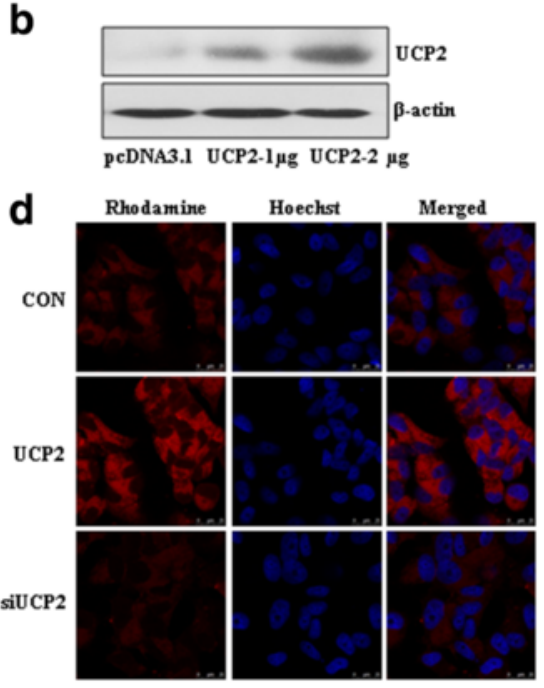

e
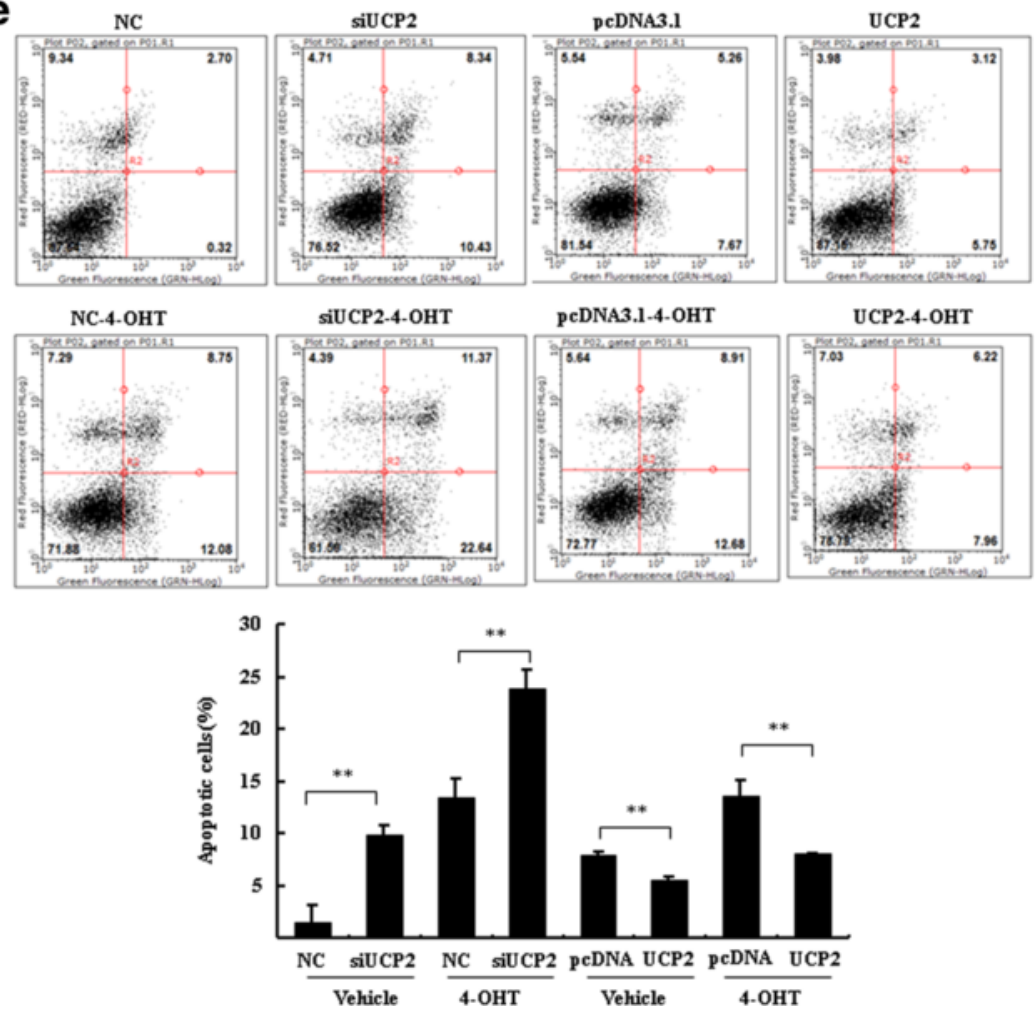
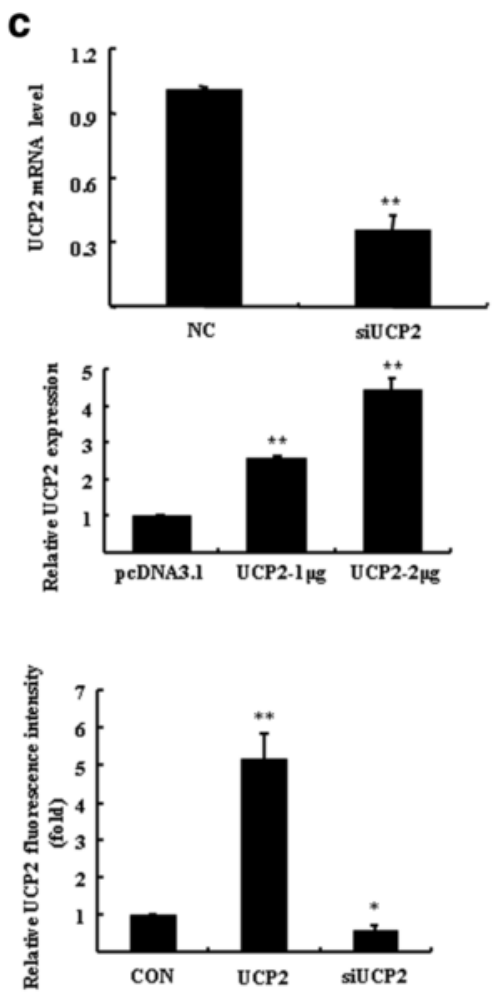$$
\text { OHT }
$$

Fig. 5 (See legend on next page.) 
(See figure on previous page.)

Fig. 5 UCP2 modulated the 4-OHT/FUL-induced apoptosis in breast cancer cells. a-c MCF7 cells were transfected with UCP2 plasmid and empty vector pcDNA3.1 or $200 \mathrm{nM}$ siRNA of UCP2 for $48 \mathrm{~h}$. RT-qPCR and Western blotting were performed to determine the expression of UCP2. The ratio UCP2/ $\beta$-actin is quantified (**P<0.01 vs. empty vector control). $\mathbf{d}$ The immunofluorescence assay was performed to analyze the expression and location of UCP2 in MCF7 cells. e Annexin V-PI staining assay was performed to determine apoptosis in MCF7 cells. Bar graphs indicated the percentage of apoptotic cells. ${ }^{*} P<0.01$ vs. negative control (NC) or empty vector control (pcDNA3.1)

OHT, whereas overexpression of UCP2 contributed to acquired endocrine resistance to 4-OHT.

\section{PI3K-Akt-mTOR pathway might be involved in the induction of autophagy by overexpression of UCP2}

We investigated the role of UCP2 in the autophagy that confers endocrine resistance. TAM and FUL crossresistant MCF7/LCC9 cells were employed in the assays. MCF7/LCC9 cells were transfected either with UCP2 plasmid or with siRNA and then exposed to 4-OHT or FUL. High level of cleaved LC3-II was observed in the UCP2 overexpressing cells, whereas low level of active form of LC3-II was detected in the UCP2 knockdown cells. These results indicated that overexpression of UCP2 induced cell autophagy in the 4-OHT/FULtreated MCF7/LCC9 cells. Consistently, the ratio of Bax// $\mathrm{Bcl}-2$ was significantly elevated in the UCP2-knockdown cells (Fig. 6a), indicating the increase of apoptosis. The induction of autophagy by UCP2 was further determined by the observation of punctate GFP-LC3 distribution in breast cancer cells. Overexpression of UCP2 induced prominent autophagy as indicated by enhanced GFP-LC3 dots. In contrast, knockdown of UCP2 inhibited the formation of autophagesomes as shown by punctate GFP-LC3, accounting for $38.3 \pm 8.8 \%$ of negative control (Fig. 6b).

To investigate the signaling pathway of autophagy regulated by UCP2, MCF7/LCC9 cells were overexpressed or knockdown UCP2 and then exposed to 4-OHT. MCF7/LCC9 cells overexpressing UCP2 showed activation of Akt and mTOR in response to 4-OHT, whereas the expressions of phospho-Akt and phospho-mTOR were significantly decreased in the UCP2-knockdown cells (Fig. 6c). Significant changes of non-phosphorylated Akt and mTOR were not observed between the UCP2overexpressing and UCP2-knockdown cells. These results indicated that the activation of the PI3K-Akt-mTOR signaling pathway might be involved in the induction of autophagy by overexpression of UCP2 in breast cancer cells.

\section{Discussion}

The development of resistance to endocrine therapy is the biggest challenge for treatment of breast cancers with TAM or FUL. Endocrine resistance to TAM or FUL was found to link with multiple reasons, such as loss of
ER, apoptosis resistance and altered expression of miRNAs [27]. Recently, studies have been focused on the aberrant regulation of autophagy in breast cancers. TAM/ FUL treatment led to apoptosis as well as autophagy in the $\mathrm{ER}^{+}$breast cancers [14]. Autophagy as a cytoprotective adaptive response usually occurs in the presence of apoptosis inductors. Molecular analysis indicated that Beclin-1, the key player in autophagy, can bind to Bcl-2 or another anti- apoptotic molecule, Bcl-xL. Beclin-1 is therefore activates the initial stages of autophagy when it is dissociated from Bcl-2 $[28,29]$. In this study, miR-214 increased the sensitivity of breast cancer cells to the TAM/FUL-induced apoptosis. Importantly, miR-214 increased the TAM/FUL-induced apoptosis while inhibited autophagy. Further study showed that miR-214 might exert its inhibitory effect on autophagy by targeting UCP2. This result was confirmed by our observation in human breast cancer tissue specimens that the levels of miR-214 were negatively correlated with UCP2. Overexpression of UCP2 contributed to endocrine resistance against TAM/FUL. We thus concluded that miR-214 inhibited the TAM/FUL induced autophagy through suppression of UCP2. MiR-214 might be developed as a novel strategy for overcoming endocrine resistance in breast cancers. These results provided new insights into the mechanism of endocrine resistance by modulation of autophagy.

Autophagy is an evolutionarily conserved catabolic process for degradation of cytoplasmic components including defective organelles and proteins. Physiologically, autophagy is implicated in cellular homeostasis by recycling of nutrients whereas defect of autophagy is associated with cancers $[30,31]$. Autophagy can act as a pro-survival mechanism or as an alternative cell death pathway to apoptosis [28]. Despite duality of autophagy, accumulated evidence revealed an important role of autophagy in the development of endocrine resistance in the $\mathrm{ER}^{+}$breast cancers [18]. Recent studies showed that the inhibition of autophagy might increase the 4-OHTinduced cytotoxicity whereas increase of autophagy is associated with endocrine resistance to 4-OHT [32]. In breast cancer cells, inhibition of autophagy by 3MA or beclin-1 siRNA potentiated the resensitization of previously antiestrogen resistant breast cancer cells $[6,14]$, suggesting a pro-survival role of autophagy in anti-estrogen therapy. 


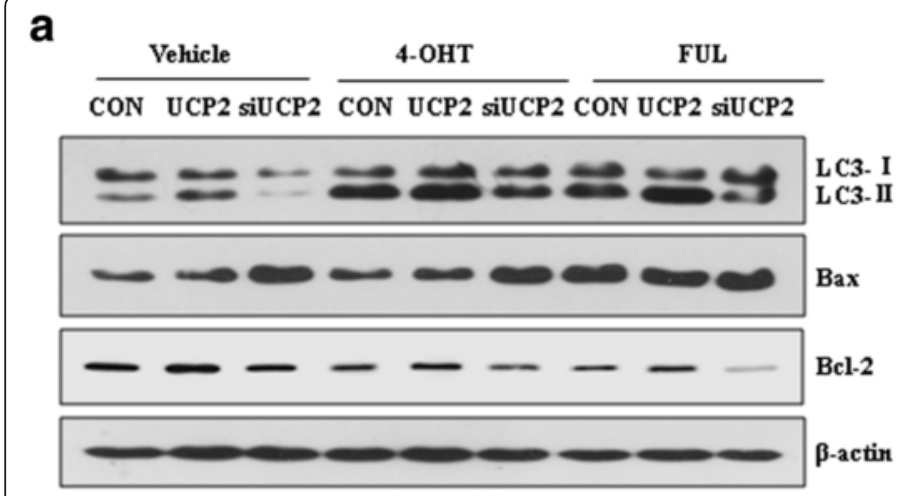

b

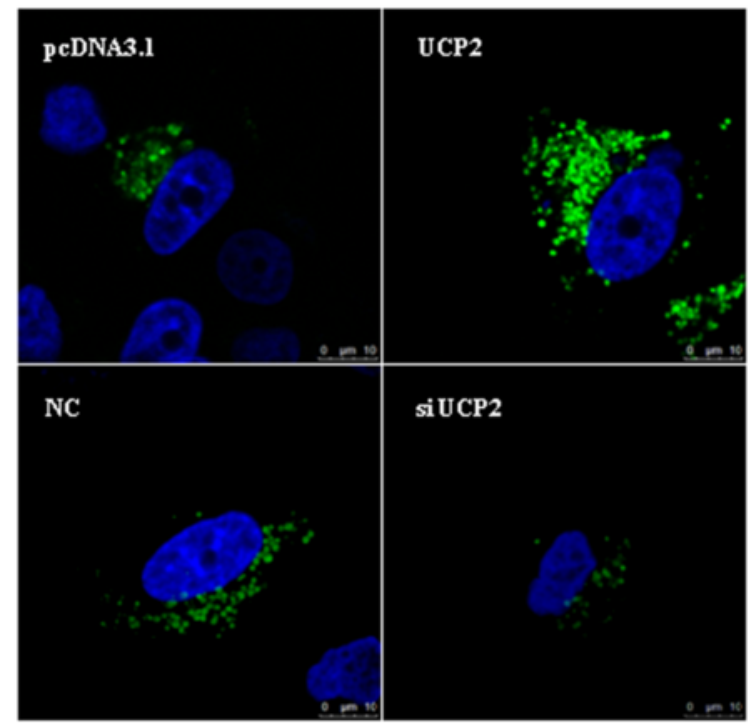

C $\frac{\text { vehicle }}{\text { pcDNA UCP2 pcDNA UCP2 }} \frac{\text { 4-OHT }}{\text { NC siUCP2 }} \frac{\text { vehicle }}{\text { NC siUCP2 }}$

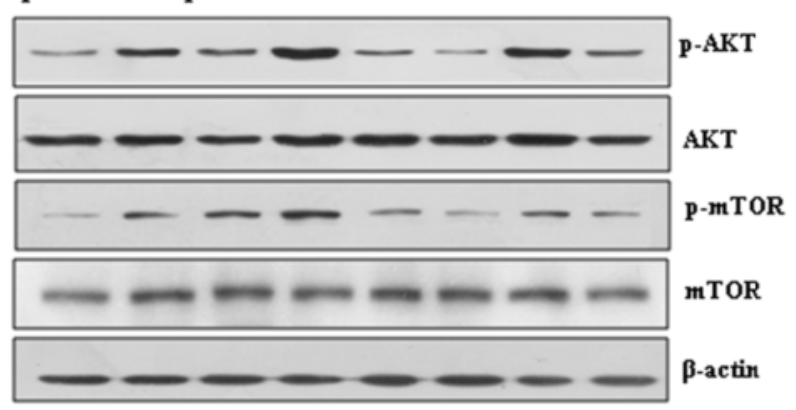

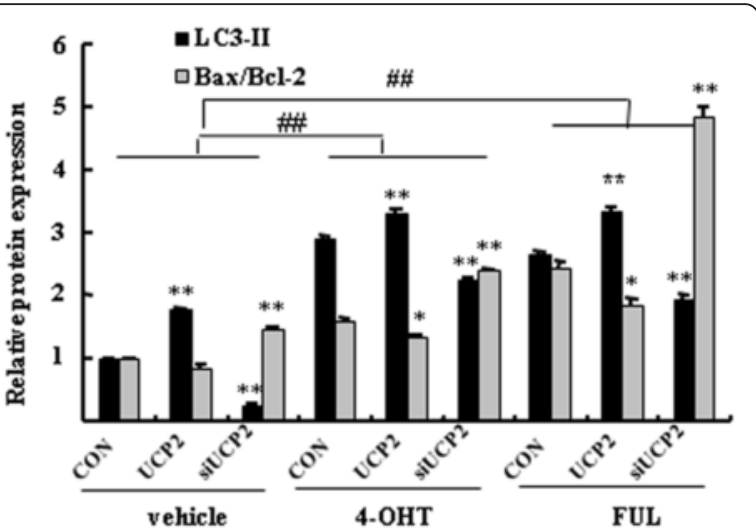
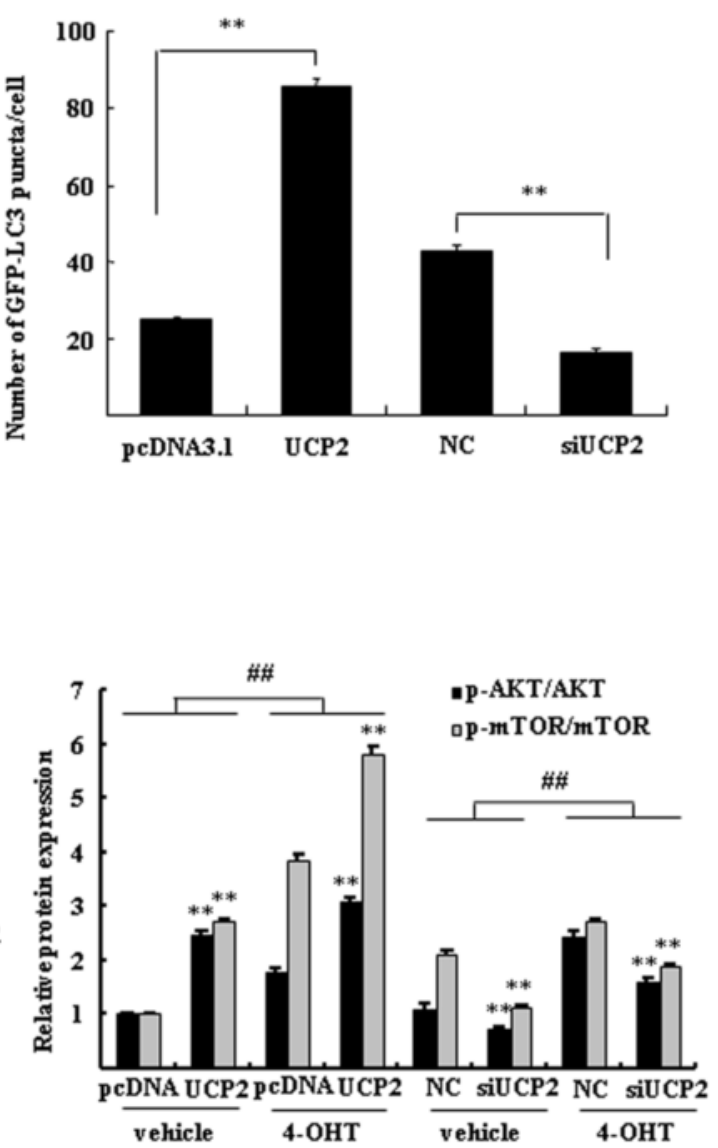

Fig. 6 UCP2 modulated autophagy through activation of the PI3K-Akt-mTOR pathway. a MCF7/LCC9 cells were transfected with UCP2 plasmid or siRNA of UCP2 for $48 \mathrm{~h}$. Western blotting was performed to analyze the expression of cleaved LC3 and the ratio of Bax/Bcl-2. Bar graphs indicated the relative levels of $L C 3-I I$ and ratio of Bax/BCl-2 normalized to $\beta$-actin. ${ }^{*} P<0.05,{ }^{*} P<0.01$ vs. control. ${ }^{\# \#} P<0.01$ vs. vehicle control. b MCF7 cells were cotransfected with GFP-LC3 together with UCP2 plasmid or $200 \mathrm{nM}$ siRNA of UCP2 for $48 \mathrm{~h}$. Cells were imaged under a confocal microscopy (scale bar $=10 \mu \mathrm{m}$ ). Numbers of GFP-LC3 puncta per cell were counted (**P<0.01 vs. empty vector control or negative control, $n=10)$. c Western blotting was performed to analyze p-Akt, Akt, p-mTOR, mTOR in MCF7/LCC9 cells. $\beta$-actin was served as loading control. Bar graphs indicated the relative levels of $p$-Akt/Akt and $\mathrm{p}$-mTOR/mTOR normalized to $\beta$-actin. ${ }^{* *} P<0.01 \mathrm{vs}$. empty vector control or negative control, ${ }^{\# \#} P<0.01 \mathrm{vs}$. vehicle control

MiRNAs are involved in the regulation of many autophagic processes, including autophagy induction, vesicle nucleation and vesicle elongation and fusion, which provides a potential for combining miRNA-based manipulation of autophagy with therapy resistance in cancers [33]. Inhibition of beclin 1-mediated autophagy by miR-30d mimic 
sensitized anaplastic thyroid carcinoma cells to cisplatin [34]. MiR-101 suppressed the tamoxifen-induced autophagy and increased the sensitivity of breast cancer cells to tamoxifen [19]. In this study, miR-214 was found to sensitize breast cancer cells to 4-OHT or FUL by inhibition of autophagy.

Accumulating studies have shed light on the potential of miR-214 as the therapeutic strategy for cancers. MiR214 was found downregulated in breast cancers [22]. MiR-214 might play pleiotropic and pivotal roles in resistance or sensitivity in various cancers. On one hand, high level of miR-214 enhanced the stemness and chemoresistance in ovarian cancers by targeting p53/Nanog [35]. MiR-214 might be responsible for chemoresistance to cisplatin or gefitinib in ovarian cancer and non small cell lung cancer $[36,37]$. On the other hand, miR-214 enhanced the cisplatin-induced cytotoxicity through down-regulation of $\mathrm{Bcl} 2 \mathrm{l} 2$ in cervical cancer cells [38]. In this study, miR-214 was found downregulated in human breast cancer tissues and decreased in response to 4-OHT/FUL. Our results showed that reduction of miR-214 was associated with elevated autophagy and endocrine resistance, while overexpression of miR-214 represses both basal and the 4OHT/FUL-induced autophagy. Further study showed that miR-214 might reduce autophagy by directly targeting UCP2.

UCP2 is a member of the family of uncoupling proteins located in inner mitochondrial membrane. UCP2 is involved in uncoupling oxidative phosphorylation and facilitating energy dissipation as heat [39]. Overexpression of UCP2 conferred drug resistance to chemotherapy and a higher survival through downregulation of ROS
[40, 41]. UCP2 was thus recognized as a negative regulator of mitochondrial ROS in many type of cancers [42]. Overexpression of UCP2 decreased intracellular ROS and attenuated apoptosis in HepG2 hepatoma cells induced by various challenges [43]. Overexpression of UCP2 protected cancer cells from the gemcitabine-induced apoptosis through decrease of mitochondrial superoxide [44]. Inhibition of UCP2 enhanced the cisplatin-induced cytotoxicity in colon cancer cells. UCP2 has been identified as a potential target for overcoming cancer chemoresistance [45]. In this study, breast cancer cells with knockdown of UCP2 showed higher sensitivity to 4-OHT than negative control cells in induction of apoptosis, whereas overexpression of UCP2 attenuated the activity of 4-OHT. Further study showed that UCP2 might play a crucial role in the induction of autophagy that confers the endocrine resistance in the TAM and FUL cross-resistant MCF7/LCC9 cells.

Recently, the PI3K/AKT/mTOR signaling pathway, which transmits signals from cell membrane into nucleus and activates multiple oncogenic programs, has been reported to play an important role in the regulation of autophagy in breast cancer cells. This signaling pathway is hyperactive in more than $70 \%$ of breast cancers. It has been revealed that the PI3K/AKT/mTOR signaling modulates the function of estrogen receptor. Activation of the PI3K-AKT-mTOR signaling is relevant to the escape of cancer cells from endocrine therapy by inhibiting the proapoptotic proteins and therefore contributes to endocrine resistance $[46,47]$. Hence, the protein kinases located along this signaling pathway represent very promising drug targets for breast cancer therapy. In this study, UCP2 was found overexpressed in breast cancer

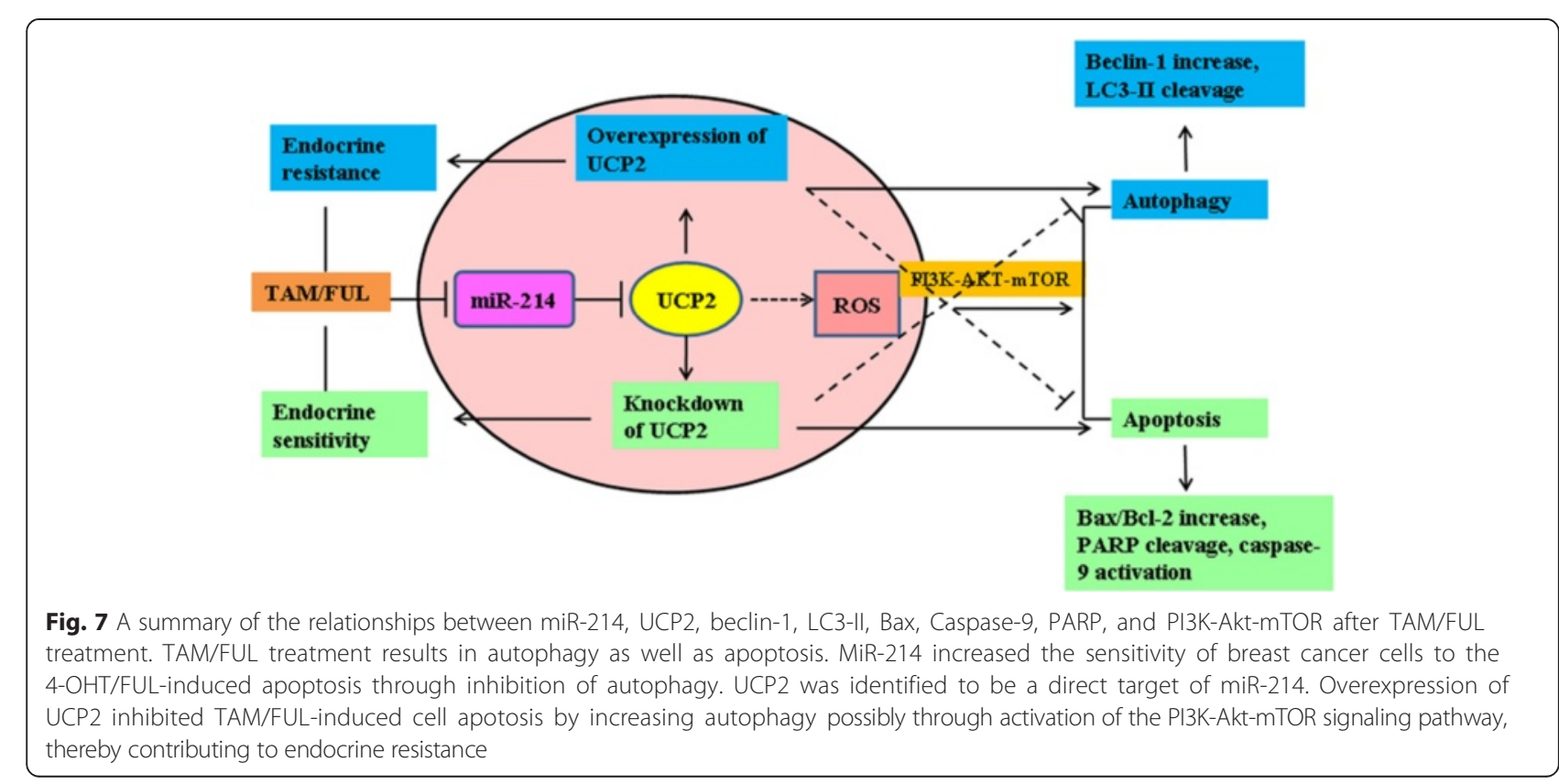


tissue specimens. Overexpression of UCP2 induced autophagy and endocrine resistance through phosphorylation of Akt and mTOR. These results suggested that the activation of the PI3K-Akt-mTOR signaling pathway might contribute to the UCP2-mediated autophagy in breast cancers. Nonetheless, there were some contradictory reports that inhibition of the PI3K-Akt-mTOR signaling pathway induced autophagy in cancer cells [12]. It has been well established that ROS modulated the autophagy process in cancer progression and chemotherapy $[48,49]$. It is hypothesized that regulation of UCP2, a critical mitochondrial protein involved in ROS production, might play a key role in coordinating autophagy and endocrine resistance through the PI3K-Akt-mTOR signaling pathway [50]. Based on currently available information, we have proposed a schematic model between miR-214, UCP2, beclin-1, LC3-I/II, Bax, Caspase9, PARP, and Akt/mTOR in the regulation of autophagy and apoptosis after TAM/FUL treatment (Fig. 7). Further studies are underway to elucidate the mechanism of UCP2-mediated autophagy in breast cancers.

\section{Conclusion}

In summary, TAM and FUL treatment induced apoptosis as well as autophagy in the $\mathrm{ER}^{+}$breast cancer cells. Autophagy is a major cause of resistance to TAM and FUL. MiR-214 increased the sensitivity of breast cancers to TAM and FUL through inhibition of autophagy by targeting UCP2. MiR-214 could be developed as a novel potential therapeutic strategy for overcoming endocrine resistance in the $\mathrm{ER}^{+}$breast cancers.

\section{Abbreviations \\ 3-MA: 3-methyladenine; 4-OHT: 4- hydroxytamoxifen; AVOs: acidic vesicular organelles; ER: estrogen receptor; FUL: fulvestrant; HER2: human epidermal growth receptor 2; MDC: monodansyl cadaverine; miRNAs: microRNAs; PR: progesterone receptor; TAM: tamoxifen; UCP2: uncoupling protein 2.}

\section{Competing interest}

We confirm that there is no potential conflict of interest or financial dependence regarding this paper.

\section{Authors' contributions}

$X Y, S W$ and WS performed the experiments. AL and ZL provided clinical specimens and analyzed data. YL contributed to plasmids construction. $X Y$ and $X Q$ analyzed data and wrote manuscript. All authors read and approved the final manuscript.

\section{Acknowledgments}

This study was supported by grants from the National Natural Science Foundation $(81201731,81173090)$. We behold genuine thankfulness to Dr. Robert Clarke (Georgetown University) for gift of MCF7/LCC9 cells and Dr. Zhihua Liu (Chinese Academy of Medical Sciences) for providing pISO vector.

\section{Author details}

'Department of Pharmacology, School of Basic Medical Sciences, Capital Medical University, No.10, Xitoutiao, Youanmenwai Avenue, 100069 Beijing, China. ${ }^{2}$ State Key Lab of Molecular Oncology, Cancer Institute \& Hospital, Chinese Academy of Medical Sciences, Beijing, China. ${ }^{3}$ Department of Pharmacology, School of Chemical Biology \& Pharmaceutical Sciences, Capital Medical University, Beijing, China.
Received: 7 March 2015 Accepted: 9 December 2015

Published online: 15 December 2015

\section{References}

1. Vergne Y, Matta J, Morales L, Vargas W, Alvarez-Garriga C, Bayona M. Breast cancer and DNA repair capacity: association with use of multivitamin and calcium supplements. Integr Med (Encinitas). 2013;12:38-46.

2. Cardoso F, Bischoff J, Brain E, Zotano AG, Luck HJ, Tjan-Heijnen VC, et al. A review of the treatment of endocrine responsive metastatic breast cancer in postmenopausal women. Cancer Treat Rev. 2013;39:457-65.

3. Mandlekar S, Kong AN. Mechanisms of tamoxifen-induced apoptosis. Apoptosis. 2001;6:469-77.

4. Bross PF, Baird A, Chen G, Jee JM, Lostritto RT, Morse DE, et al. Fulvestrant in postmenopausal women with advanced breast cancer. Clin Cancer Res. 2003;9:4309-17.

5. Ciruelos E, Pascual T, Arroyo Vozmediano ML, Blanco M, Manso L, Parrilla L, et al. The therapeutic role of fulvestrant in the management of patients with hormone receptor-positive breast cancer. Breast. 2014;23:201-8.

6. Qadir MA, Kwok B, Dragowska WH, To KH, Le D, Bally MB, et al. Macroautophagy inhibition sensitizes tamoxifen-resistant breast cancer cells and enhances mitochondrial depolarization. Breast Cancer Res Treat. 2008;112:389-403.

7. Rao X, Di Leva G, Li M, Fang F, Devlin C, Hartman-Frey C, et al. MicroRNA221/222 confers breast cancer fulvestrant resistance by regulating multiple signaling pathways. Oncogene. 2011;30:1082-97.

8. Zhao M, Ramaswamy B. Mechanisms and therapeutic advances in the management of endocrine-resistant breast cancer. World J Clin Oncol. 2014; 5:248-62.

9. Clarke R, Skaar TC, Bouker KB, Davis N, Lee YR, Welch JN, et al. Molecular and pharmacological aspects of antiestrogen resistance. J Steroid Biochem Mol Biol. 2001;76:71-84.

10. Bursch W, Ellinger A, Kienzl H, Torok L, Pandey S, Sikorska M, et al. Active cell death induced by the anti-estrogens tamoxifen and ICI 164384 in human mammary carcinoma cells (MCF-7) in culture: the role of autophagy. Carcinogenesis. 1996;17:1595-607.

11. Nepal S, Kim MJ, Hong JT, Kim SH, Sohn DH, Lee SH, et al. Autophagy induction by leptin contributes to suppression of apoptosis in cancer cells and xenograft model: involvement of p53/FoxO3A axis. Oncotarget. 2015;6:7166-81.

12. Zhao GX, Pan $H$, Ouyang DY, He XH. The critical molecular interconnections in regulating apoptosis and autophagy. Ann Med. 2015;47:305-15.

13. He C, Klionsky DJ. Regulation mechanisms and signaling pathways of autophagy. Annu Rev Genet. 2009;43:67-93.

14. Samaddar JS, Gaddy VT, Duplantier J, Thandavan SP, Shah M, Smith MJ, et al. A role for macroautophagy in protection against 4-hydroxytamoxifeninduced cell death and the development of antiestrogen resistance. Mol Cancer Ther. 2008;7:2977-87.

15. Schwartz-Roberts $\mathrm{L}$, Cook KL, Chen C, Shajahan-Haq AN, Axelrod M, Warri $A$, et al. Interferon regulatory factor-1 signaling regulates the switch between autophagy and apoptosis to determine breast cancer cell fate. Cancer Res. 2015:75:1046-55.

16. Lai EC. Micro RNAs are complementary to $3^{\prime}$ UTR sequence motifs that mediate negative post-transcriptional regulation. Nat Genet. 2002;30:363-4.

17. Ambros V. microRNAs: tiny regulators with great potential. Cell. 2001;107:823-6.

18. Chen Y, Fu LL, Wen X, Liu B, Huang J, Wang JH, et al. Oncogenic and tumor suppressive roles of microRNAs in apoptosis and autophagy. Apoptosis. 2014;19:1177-89.

19. Frankel LB, Wen J, Lees $M$, Hoyer-Hansen M, Farkas T, Krogh A, et al. microRNA-101 is a potent inhibitor of autophagy. Embo J. 2011;30:4628-41.

20. Sharma T, Hamilton R, Mandal CC. miR-214: a potential biomarker and therapeutic for different cancers. Future Oncol. 2015;11:349-63.

21. Schwarzenbach $H$, Milde-Langosch $K$, Steinbach B, Muller V, Pantel K. Diagnostic potential of PTEN-targeting miR-214 in the blood of breast cancer patients. Breast Cancer Res Treat. 2012;134:933-41.

22. Derfoul A, Juan AH, Difilippantonio MJ, Palanisamy N, Ried T, Sartorelli V. Decreased microRNA-214 levels in breast cancer cells coincides with increased cell proliferation, invasion and accumulation of the Polycomb Ezh2 methyltransferase. Carcinogenesis. 2011;32:1607-14.

23. Cheng AM, Byrom MW, Shelton J, Ford LP. Antisense inhibition of human miRNAs and indications for an involvement of miRNA in cell growth and apoptosis. Nucleic Acids Res. 2005;33:1290-7. 
24. Lippman M, Bolan G, Huff K. The effects of estrogens and antiestrogens on hormone-responsive human breast cancer in long-term tissue culture. Cancer Res. 1976;36:4595-601.

25. Livak KJ, Schmittgen TD. Analysis of relative gene expression data using real-time quantitative PCR and the 2(-Delta Delta C(T)) Method. Methods. 2001;25:402-8.

26. Tian Y, Luo A, Cai Y, Su Q, Ding F, Chen H, et al. MicroRNA-10b promotes migration and invasion through KLF4 in human esophageal cancer cell lines. J Biol Chem. 2010:285:7986-94.

27. Garcia-Becerra R, Santos N, Diaz L, Camacho J. Mechanisms of resistance to endocrine therapy in breast cancer: focus on signaling pathways, miRNAs and genetically based resistance. Int J Mol Sci. 2012;14:108-45.

28. Cook KL, Shajahan AN, Clarke R. Autophagy and endocrine resistance in breast cancer. Expert Rev Anticancer Ther. 2011;11:1283-94.

29. Levine B, Sinha S, Kroemer G. Bcl-2 family members: dual regulators of apoptosis and autophagy. Autophagy. 2008;4:600-6.

30. Levine B, Kroemer G. Autophagy in the pathogenesis of disease. Cell. 2008;132:27-42.

31. Chen N, Debnath J. Autophagy and tumorigenesis. FEBS Lett. 2010;584: 1427-35.

32. Duan L, Danzer B, Levenson W, Maki CG. Critical roles for nitric oxide and ERK in the completion of prosurvival autophagy in 4OHTAM-treated estrogen receptor-positive breast cancer cells. Cancer Lett. 2014;353:290-300.

33. Frankel LB, Lund AH. MicroRNA regulation of autophagy. Carcinogenesis. 2012;33:2018-25.

34. Zhang Y, Yang WQ, Zhu H, Qian YY, Zhou L, Ren YJ, et al. Regulation of autophagy by miR-30d impacts sensitivity of anaplastic thyroid carcinoma to cisplatin. Biochem Pharmacol. 2014;87:562-70.

35. Jemal A, Siegel R, Xu J, Ward E. Cancer statistics, 2010. CA Cancer J Clin. 2010;60:277-300.

36. Yu X, Zhang X, Bi T, Ding Y, Zhao J, Wang C, et al. MiRNA expression signature for potentially predicting the prognosis of ovarian serous carcinoma. Tumour Biol. 2013;34:3501-8.

37. Wang YS, Wang YH, Xia HP, Zhou SW, Schmid-Bindert G, Zhou CC. MicroRNA214 regulates the acquired resistance to gefitinib via the PTEN/AKT pathway in EGFR-mutant cell lines. Asian Pac J Cancer Prev. 2012;13:255-60.

38. Wang F, Liu M, Li X, Tang H. MiR-214 reduces cell survival and enhances cisplatin-induced cytotoxicity via down-regulation of $\mathrm{BC} / 2 \mathrm{l} 2$ in cervical cancer cells. FEBS Lett. 2013;587:488-95.

39. Fleury C, Neverova M, Collins S, Raimbault S, Champigny O, Levi-Meyrueis C, et al. Uncoupling protein-2: a novel gene linked to obesity and hyperinsulinemia. Nat Genet. 1997;15:269-72.

40. Kowaltowski AJ, de Souza-Pinto NC, Castilho RF, Vercesi AE. Mitochondria and reactive oxygen species. Free Radic Biol Med. 2009;47:333-43.

41. Derdak Z, Mark NM, Beldi G, Robson SC, Wands JR, Baffy G. The mitochondrial uncoupling protein-2 promotes chemoresistance in cancer cells. Cancer Res. 2008;68:2813-9.

42. Mattiasson G, Sullivan PG. The emerging functions of UCP2 in health, disease, and therapeutics. Antioxid Redox Signal. 2006;8:1-38.

43. Collins P, Jones C, Choudhury S, Damelin L, Hodgson H. Increased expression of uncoupling protein 2 in HepG2 cells attenuates oxidative damage and apoptosis. Liver Int. 2005;25:880-7.

44. Dalla Pozza E, Fiorini C, Dando I, Menegazzi M, Sgarbossa A, Costanzo C, et al. Role of mitochondrial uncoupling protein 2 in cancer cell resistance to gemcitabine. Biochim Biophys Acta. 1823;2012:1856-63.

45. Santandreu FM, Roca P, Oliver J. Uncoupling protein-2 knockdown mediates the cytotoxic effects of cisplatin. Free Radic Biol Med. 2010;49:658-66.

46. Tokunaga E, Hisamatsu Y, Tanaka K, Yamashita N, Saeki H, Oki E, et al. Molecular mechanisms regulating the hormone sensitivity of breast cancer. Cancer Sci. 2014;105:1377-83.

47. Nicolini A, Ferrari P, Kotlarova L, Rossi G, Biava PM. The PI3K-AKt-mTOR pathway and new tools to prevent acquired hormone resistance in breast cancer. Curr Pharm Biotechnol. 2015;16:804-15.

48. Kongara S, Karantza V. The interplay between autophagy and ROS in tumorigenesis. Front Oncol. 2012;2:171.

49. Li ZY, Yang Y, Ming M, Liu B. Mitochondrial ROS generation for regulation of autophagic pathways in cancer. Biochem Biophys Res Commun. 2011;414:5-8.

50. Schumacker PT. Reactive oxygen species in cancer cells: live by the sword, die by the sword. Cancer Cell. 2006;10:175-6.

\section{Submit your next manuscript to BioMed Central and we will help you at every step:}

- We accept pre-submission inquiries

- Our selector tool helps you to find the most relevant journal

- We provide round the clock customer support

- Convenient online submission

- Thorough peer review

- Inclusion in PubMed and all major indexing services

- Maximum visibility for your research

Submit your manuscript at www.biomedcentral.com/submit
Biomed Central 